\title{
Diary-keeping as a sex-role behavior
}

\author{
CHARLES P. THOMPSON \\ Kansas State University, Manhattan, Kansas 66506
}

\begin{abstract}
Two surveys on diary-keeping were conducted in a young adult population. The data showed that many more women than men kept diaries. However, an equal proportion of male and female diary-keepers would allow inspection of their diaries.
\end{abstract}

Naturally occurring diaries are a potentially useful source of information for investigation of a number of phenomena, including memory for personal events (Thompson, in press). Before one can use naturally occurring diaries, however, several questions must be resolved. At the outset, one needs to know the frequency with which diaries are kept and which individuals would allow inspection of their diaries. It seemed quite possible that the answers to both questions would reveal behavior conforming to sex-role expectations.

In the latter case, it is clear that inspection of a diary involves some degree of self-disclosure on the part of the owner of the diary. Prior research on self-disclosure has frequently shown that women are willing to reveal more personal information than men are (e.g., Jourard \& Lasakow, 1958), although there are many exceptions to that result (e.g., Plog, 1965). Thus, the literature on selfdisclosure would lead one to expect that women might be more likely than men to allow inspection of a personal diary.

Women also might be more likely to keep diaries than men are. Diary-keeping is a reflective and relatively passive activity. The characteristics of passivity and reflectiveness would seem to fit the sex-role stereotype for women and run counter to the stereotype for men. Because we think that behavior is determined in part by sex-role expectations, we expected more women than men to keep diaries.

To check the hypotheses that both frequency of diary-keeping and willingness to allow inspection of the diaries would be sex-related behavior, we conducted two surveys.

\section{SURVEY 1}

\begin{abstract}
Method
Subject population. The subjects in the first survey were 148 students in a large introductory psychology class.

Questionnaire. The questionnaire used in the survey was quite short. It was identified as a journal questionnaire and consisted of eight questions in addition to asking for name, age, and sex of the respondent. The questions asked whether the respondent had kept a journal, (if so) for how long, and the estimated
\end{abstract}

The author wishes to express his appreciation to Beverly Biggs and Aleda Oetinger for their assistance in collecting and tabulating the data. starting and stopping dates of the journal. In addition, the respondent was asked how frequently entries were made in the journal and how often the journal was read during the journal period and after it was completed. Finally, the respondent was asked to estimate the last date on which the journal was read.

A short section at the bottom of the questionnaire asked the respondents to fill in their address and phone number if they were interested in having their memory tested using entries from their journal.

Procedure. We briefly described to the class our interest in naturally occurring memory and our notion that such memory might be studied through the use of journals. We noted that we first had to find out how many people kept journals and, in addition, how many might be willing to let us use those journals for the purpose of testing memory. The questionnaire was then distributed with the qualification that those not wishing to participate need not do so. Although time pressure precluded a completely accurate count of class attendance, it is clear that the number refusing to participate could not have exceeded $5 \%$ and was probably much closer to $1 \%$.

\section{Results and Discussion}

Much to our astonishment, $77 \%$ of the students reported keeping a journal (114 of 148 students). However, many of the students made comments in answering the questions that indicated that journals were mandatory in the English composition course required of all students. In spite of that requirement's presumably producing a strong bias toward all students' keeping journals, proportionally more women than men appeared to have kept journals. The frequency of journal-keeping by sex is presented in Table 1.

The difference between sexes was statistically reliable $\left[\chi^{2}(1)=12.19, \mathrm{p}<.01\right]$. Expressed as percentages, $91 \%$ of the women kept journals, compared with $65 \%$ of the men.

Table 1

Distribution of Men and Women Partitioned into Those Who Kept Diaries and Those Who Did Not

\begin{tabular}{|c|c|c|c|c|c|c|}
\hline & \multirow[b]{2}{*}{ Kept Journals? } & \multicolumn{2}{|c|}{ Men } & \multicolumn{2}{|c|}{ Women } & \multirow[b]{2}{*}{$\mathbf{N}$} \\
\hline & & Yes & No & Yes & No & \\
\hline Survey 1 & $\begin{array}{l}\text { All Journals } \\
\text { Nonrequired Journals }\end{array}$ & $\begin{array}{l}53 \\
32\end{array}$ & $\begin{array}{l}28 \\
49\end{array}$ & $\begin{array}{l}61 \\
37\end{array}$ & $\begin{array}{r}6 \\
30\end{array}$ & $\begin{array}{l}148 \\
148\end{array}$ \\
\hline Survey 2 & $\begin{array}{l}\text { All Journals } \\
\text { Nonrequired Journals }\end{array}$ & $\begin{array}{r}69 \\
8\end{array}$ & $\begin{array}{l}33 \\
94\end{array}$ & $\begin{array}{r}107 \\
43\end{array}$ & $\begin{array}{l}23 \\
87\end{array}$ & $\begin{array}{l}232 \\
232\end{array}$ \\
\hline
\end{tabular}

Note-The data are entered separately for all journals and for nonrequired journals only. The data are also entered separately for each survey. 
The inclusion of required journals is obviously a problem. As a first approximation to estimating the frequency of nonrequired journals, we went through the questionnaires and eliminated all journals with a duration matching a college semester. This procedure produced an estimate of frequency of journal-keeping markedly reduced from the original. The overall frequency of estimated nonrequired journal-keeping was $47 \%$. The frequency distribution for estimated nonrequired journals is also presented in Table 1.

Interestingly, while the relative frequency of journalkeeping was still numerically greater for women (55\%) than for men (40\%), that result was only marginally statistically significant $\left[\chi^{2}(1)=3.04, .1>p>.05\right]$.

The questionnaire data, then, tend to support the hypothesis that diary-keeping is a sex-related behavior. However, as noted above, when an attempt is made to eliminate required journal-keeping, the effect is statistically marginal.

The second question of interest is whether there are sex differences in allowing inspection of a journal. Here, of course, we need to do a conditional analysis, asking those with journals whether or not they will allow inspection of those journals. The relevant data are presented in Table 2 for both all journals and the estimated rate of nonrequired journals. Analyses of those data show no reliable differences between sexes $\left[\chi^{2} s<1\right)$. Indeed, inspection of the data shows that the numerical trend suggests proportionately more males than females offered their journals for inspection.

In summary, the data from this survey suggest that more women than men keep journals but that men are as likely as women to offer their diaries for inspection.

As noted earlier, the survey revealed that many of the journals reported were kept as a class exercise. Because we cannot sort out those journals with certainty from journals kept as a matter of personal choice, we cannot use these data to assert that frequency of journalkeeping is sex-related. The questionnaire was changed for the second survey to remedy that defect.

Table 2

Distribution of Diary-Keeping Men and Women Partitioned into Those Who Will Allow Inspection of Their Diaries and Those Who Will Not

\begin{tabular}{llrrrrr}
\hline & & \multicolumn{3}{c}{ Men } & \multicolumn{3}{c}{ Women } \\
& \multicolumn{1}{c}{ Permit Use? } & Yes & No & Yes & No & N \\
\hline \multirow{2}{*}{ Survey 1} & All Journals & 8 & 45 & 6 & 55 & 114 \\
& Nonrequired Journals & 6 & 26 & 4 & 33 & 69 \\
Survey 2 & All Journals & 15 & 54 & 18 & 89 & 176 \\
& Nonrequired Journals & 0 & 8 & 5 & 38 & 51 \\
\hline
\end{tabular}

Note-The data are entered separately for all journals and for nonrequired journals only. The data are also entered separately for each survey.

\section{SURVEY 2}

\section{Method}

Subject population. The subjects were 232 students in a large introductory psychology class.

Questionnaire. The questionnaire was virtually identical to that used in the first survey, with the exception that subjects were asked whether they were required to keep the journal.

Procedure. The procedure was identical to that used in the first survey. Again, a rough count of class attendance indicated that the number refusing to participate could not have exceeded $5 \%$ and was probably around $1 \%$.

\section{Results and Discussion}

When the required journals were included, the percentage of respondents keeping a journal was $76 \%$, almost identical to the first survey (77\%). The number of men and women keeping and not keeping journals is shown in Table 1 for all journals and for nonrequired journals only.

An analysis of the data for all journals showed that relatively more women than men kept journals $\left[\chi^{2}(1)=5.93, p<.02\right]$. Translated to percentages, $68 \%$ of the men kept journals, compared with $82 \%$ of the women.

An analysis of the data for the nonrequired journals showed exactly the same pattern $\left[\chi^{2}(1)=19.77, \mathrm{p}<.01\right]$. In the case of nonrequired journals, $8 \%$ of the men kept journals, compared with $33 \%$ of the women.

Note that with an objective measure of nonrequired journal-keeping, we found that $22 \%$ of the respondents kept journals. This is far below our attempted estimate $(47 \%)$ in the first survey.

Turning to the question regarding which respondents would allow us to view their journals, the relevant data are summarized in Table 2 for both all journals and nonrequired journals.

As in the first survey, the analyses on these data showed no reliable differences between the sexes $\left(\chi^{2} s<1\right)$.

\section{GENERAL DISCUSSION}

Sex-related behavior is pervasive in society, and diary-keeping is no exception. The results of the two surveys rather clearly show that diary-keeping is sex-related. On the other hand, both sexes are equally likely to permit inspection of an existing diary.

While the fact that diary-keeping is sex-related may not be surprising, the magnitude of effect was. The best estimate of the effect is undoubtedly from the second survey, which shows that four times more women than men keep diaries.

In contrast to our initial expectations, these data show that men are as likely as women to allow their diaries to be inspected. Note that this result holds both for nonrequired diaries and for all diaries. On the surface, these results would appear to conflict with the majority of results on self-disclosure (e.g., Cozby, 1973; Jourard \& Lasakow, 1958). However, we only asked that we be allowed to inspect the diaries and did not attempt to evaluate the contents of the diaries. Such an evaluation might well show that the type of entry in a diary, as well as the frequency of diary-keeping, is sex-related. Specifically, women might include 
more intimate incidents in their diaries than men. In support of this view, an earlier study by Pederson and Breglio (1968) showed that women disclosed more intimate information about themselves in a written self-description than did men. Thus, permitting inspection of diaries could involve more self-disclosure for women than for men, even though the relative frequency of inspection was the same for both sexes.

We would suggest that the only effect of using a restricted college population in our two surveys is to make our estimates of the frequency of diary-keeping somewhat higher than would be found for all young adults, but that it is still a good first approximation. Further, because there is no evidence to suggest that sex-related behavior occurs more (or less) frequently among college students, the relative proportion of male and female diary-keepers is probably accurately determined by our survey.

In summary, diary-keeping in young adults is clearly sexrelated behavior. Somewhat surprisingly, however, both sexes are equally likely to permit inspection of their diaries. The latter fact cannot be used to conclude that the sexes are equivalent in self-disclosure. To do that, the content of the diaries would have to be equivalent and the content of diaries was not addressed in these surveys.

\section{REFERENCES}

Cozby, P. C. Self-disclosure: A literature review. Psychological Bulletin, 1973, 79, 73-91.

Jourard, S. M., \& Lasakow, P. Some factors in self-disclosure. Journal of Abnormal and Social Psychology, 1958, 56, 91-98.

Pederson, D. M., \& Breglio, V. J. Personality correlates of actual self-disclosure. Psychological Reports, 1968, 22, 495-501.

Plog, S. C. The disclosure of self in the United States and Germany. Journal of Social Psychology, 1965, 65, 193-203.

Thompson, C. P. Memory for unique personal events: The roommate study. Memory \& Cognition, in press.

(Received for publication June 4, 1982.) 